\title{
Ambidextrous Utilisation of Artificial Intelligence in Policing: A Conceptual Framework
}

\author{
Tuomas Korhonen, Ossi Heino \& Teemu Laine
}

\begin{abstract}
This conceptual paper contributes to the literature by showing the need to understand artificial intelligence (AI) in policing outside the task-dependent environment of today. We examine AI in policing by outlining its potential opportunities and challenges in exploration for today's policing tasks and beyond. Based on these findings, we reflect upon Holmqvist's prior theorisation of the dynamics of organizational ambidexterity (i.e., exploitation and exploration). The paper offers future research avenues for public administration and general management researchers interested in AI.
\end{abstract}

Keywords: Policing, Police, Artificial intelligence, Public administration, Ambidexterity

\section{INTRODUCTION}

The problems of today easily prevail in the task-dependent environment of the police (Huotari 2021). Generally, the police can be defined as the 'body of officers representing the civil authority of government'; thus, the taskdependent environment of the police consists of being 'responsible for maintaining public order and safety, enforcing the law, and preventing, detecting, and investigating criminal activities. These functions are known as policing.' (Whetstone et al. 2020). The key tasks of policing hence relate to areas like public order, crime, public safety, vulnerable people, emergencies, and crises (Rogers \& Lewis 2007). While these tasks might often be acute, they do not only depend on today's problems but concern the future as well. And as we do not know which kinds of threats lie in the future, solving the problems of today is not enough for policing
(Egbert \& Leese 2021; Smith \& Umans 2015); therefore, the police need new innovations as well (Huotari 2021). However, real disruptive innovations are difficult to achieve in the policing context as 'compliance', 'conformity', 'task performance' and 'egalitarianism' in the form of levelling of individuals prevail; a new idea is not necessarily a valued thing in the police culture (Huotari 2021, 116).

Naturally, the task of the police is not to be innovative per se, but to perform well in the tasks assigned to them. The question is how to balance between addressing known problems more efficiently (i.e., exploiting existing possibilities) and going beyond the problems already known (i.e., exploring); such balancing can be defined as ambidexterity (e.g., Tushman \& O’Reilly 1996; March 1991).

In this article, we define exploration and exploitation as follows: 'Exploration includes things captured by terms such as search, variation, risk taking, experimentation, play, flexibility, discovery, [and] innovation'; in contrast, 'Exploitation includes such things as refinement, choice, production, efficiency, selection, implementation, [and] execution.' (March 1991, 71). To increase societal preparedness for undesired events (McCulloch \& Wilson 2016), policing requires ambidextrous innovativeness, i.e., both exploration and exploitation of resources and knowledge. One source of such innovativeness in policing stems from technologies, e.g., artificial intelligence (AI) which is the focus of this special issue in the Journal of Administrative Studies. Due to its potential benefits, AI is expected to permeate many if not all functions of society in one way or another and help people do things that they have not even thought of before (Olsen et al. 2020). 
From the wider perspective of public administration, there is a need for administrators to prevent new technologies, such as AI, from becoming disconnected from the context in which they are used (Autioniemi 2020; Eloranta 1986). AI could well increase the value of administration for the citizen by enabling officials to improve service provision (Mehr 2017), by helping them do something that was not possible before (Anastasopoulos \& Whitford 2019), or by helping them mitigate resource scarcity by making administration tasks more efficient (Wirtz et al. 2020; Mehr 2017). However, utilising AI is far from unproblematic and requires critical scrutiny (e.g., Hälterlein 2021; Leese 2021; Autioniemi 2020; Kaufmann 2019).

As AI is still a technology not widely used across professions (although far from new, see e.g., Sun \& Medaglia 2019; and cf., Eloranta 1986), many types of experimentation with AI could be labelled as exploration (cf. March 1991). Today's task-dependent environment poses a philosophical challenge here: if one picks up a never-before-seen technological artefact (such as $\mathrm{AI}$ ), and starts experimenting with it by using it as a hammer, could this be called exploration? In this article we claim that hardly it would - at least regarding the wide array of opportunities (and challenges) possibly missed. Hitting a nail with a new object is at least near to exploitation of that object, even if it was called exploration. Recent studies show that unaddressed questions remain concerning how this new artefact would change or shape the individual's very existence and activities of their organization, or even the society (Girasa 2020; Berk 2021; Bain 2016). Moreover, in the hammer example, known problem-formulation would guide AI, not the other way around (Berk 2021; Egbert \& Leese 2021). In more general terms, enhancing the capacity to solve known problems is unlikely to provide solutions for solving problems that are not yet known to administrators. Emphasising exploitation will inevitably lead to the desired goals in its own assessment framework (Skogan 2006). This way, AI could become little more than emperor's new clothes for policing (Shapiro 2021). Altogether, if AI is myopically harnessed to serve only short-term efficiency, long-term effectiveness might be sacrificed (Huotari 2021).
Hence, in this article, we approach exploration from two perspectives: inside and outside the task-dependent environment of today. Our research question is: what are the opportunities and challenges for exploration with AI in policing, inside and outside today's task-dependent environment?

The opportunities-challenges approach to AI has been increasingly present in academic research on AI (Autioniemi 2020) and has been elaborately covered in recent administrative studies (see e.g., Wirtz 2020). In this article, our intention is not to summarise all the previous literature on the opportunities and challenges of AI in public administration. Rather, we wish to inspire the conceptual analysis of AI precisely in the context of policing and thus pave the way for AI-supported policing capable of solving issues that are not even known of yet. This insight will contribute to developing the rationale and epistemic background of AI in policing (Hälterlein 2021). We know AI has implications for policing and ambidexterity therein (Bland 2020; Macnish et al. 2020) - yet there is still inadequate understanding about how to build new amidst the existing (Huotari 2021). Moreover, AI in policing is a particularly relevant area of study since policing is expected to transform in the future exactly because of AI (Joh 2017).

How could policing be supported by AI from inside and outside today's task-dependent environment, then? To begin with, we define what $\mathrm{AI}$ is. AI refers to technologies that enable computers and machines to mimic the learning, problem-solving, and decision-making capabilities inherent for human beings (Kelleher 2019). From the technological perspective, '[a] rtificial intelligence is the programming of computers to do tasks that would normally require human intelligence. This includes the ability to understand and monitor visual/ spatial and auditory information, reason and make predictions, interact with humans and machines, and continuously learn and improve.' (Mehr 2017, 3.) In this article, we consider AI as a technology that does not require ex ante theoretical models, but rather, it uses data to detect possible patterns and associations within e.g., crime-related, individual-related or 
societal data (Hälterlein 2021). Despite this, the algorithms that AI runs on have been written, trained, and operated by people which means that AI is not completely free from human agency either (Kaufmann 2019).

In this article, we claim that to supplement more closed, task-dependent exploration with AI in policing (which is near to exploitation), one needs to open up to exploration under an assessment framework that is not only pre-determined by the task environment of today. Howewer, at some point, even the new, outside-of-the-box innovations could require reconnection to the work processes of the police, perhaps focusing on certain analytics that have been seen as purposeful. As a particularly suitable framework to understand such dynamics, we draw upon Holmqvist's (2003) 'dynamic model of intra- and interorganizational learning' to understand the conceptual nature of ambidexterity. Holmqvist's theorisation allows us to understand how the higher extent of bureaucracy (hierarchy, rules and power relations) leads to an exploitational mode of learning whereas exploration might require escaping this bureaucracy, by 'opening up' to new opportunities.

The article is structured as follows: first, we look at the police and policing as a technological context. After that, we go deeper into Holmqvist's (2003) framework. We then present our analysis of AI in policing, from the viewpoint of exploration both inside and outside today's task-dependent environment. The article ends with conclusions, future research directions and administrative implications.

\section{POLICING AS A TECHNOLOGICAL CHANGE CONTEXT}

Operations of the police, in the sense of law enforcement, are based on legislation that defines areas of competences and conferred powers that, through strategies and official documents are translated into police practices (Rowe 2014). The police are in constant interaction with other forms of policing, which is why the police must stay on track with crime problems, community concerns, and technological developments as well (Braga \& Weisburd 2006). And indeed, the police have developed (Weisburd \& Braga 2006).
However, it is still always debatable in what sense a development has ultimately changed the identity of police, how it serves the purposes of policing, and in what sense it presents just new ways to justify already established approaches (Braga \& Weisburd 2006). This criticism is understandable since radical or even paradigmatic changes often challenge the existing structures and practices that have proven their accuracy in many respects and have strengthened their position and legitimacy throughout history (Huotari 2021). Yet, without change and innovations and a future-oriented approach, the police will increasingly face problems that they are unable to address.

One key source that has necessitated continuous response from policing is technology, which has had a key impact on police organizations and practices (Bain 2016). Keeping up with technological development is central, as the technological capacity also serves as a potential game-changer for the police; potentially the technological capacity could help the police target its interventions, e.g., disrupt organised crime and terrorism effectively (Lehr 2019; McCulloch \& Wilson 2016; Staniforth \& Akhgar 2015).

Understandably, technology has been a key component in many strategic innovations and reforms of police service, but how technologies and innovations relate to policing is yet to be thoroughly scrutinised (Huotari 2021). Policing becomes embedded in socio-technical structures, as technologies and their users both consciously and unconsciously contribute to pre-determined policing goals (Hälterlein 2021; Leese 2021). Important questions lie in what sense technology pushes policing on those tracks it already runs (Berk 2021), how much it contributes to standardisation of risks which shrinks 'the space for alternative perspectives and solutions' (Olsen et al. 2020, 11), and in what sense it enables the construction of new tracks for the police to better serve the very purposes of policing in contemporary societies - i.e., maintaining the societal order and, when needed, adapting to changes to fulfil this purpose (Skogan 2006). How then could policing harness the potential embedded in new technologies, such as AI (Brewster et al. 2015)? 
As we will see, AI provides both opportunities and challenges for policing. Technologies will not necessarily provide needed policing reforms, but they might be needed as enablers to make those reforms happen if policing is to become ambidextrous. What is not yet known is how AI could change policing without strengthening those structures that partially produce insecurity in the first place. Such knowledge could be acquired once the police not only try to exploit AI but also explore with it. We go into this issue in the next section, by drawing upon Holmqvist's (2003) work.

\section{HOLMQVIST'S MODEL OF AMBIDEXTROUS ORGANIZATIONAL LEARNING}

In his article published in Organization Studies, Mikael Holmqvist (2003) offers a rich theorisation of organizational ambidexterity, based on intra- and interorganizational learning. According to him, while the boundaries, bureaucracies and power relationships of an organization might hinder exploration, more exploratory modes of learning might be allowed in inter-organizational settings. In essence, Holmqvist provides a model of learning that includes a loop of exploitation and exploration and the dynamics between these two (Figure 1). In Holmqvist's $(2003,107)$ vocabulary: 'Acting occurs when the organization is in an ongoing process of exploitation'; 'Openingup comes about when the organization moves from a process of exploitation to a process of exploration'; 'Experimenting takes place when the organization is in an ongoing process of exploration'; and finally, 'Focusing occurs when the organization moves from a process of exploration to a process of exploitation.

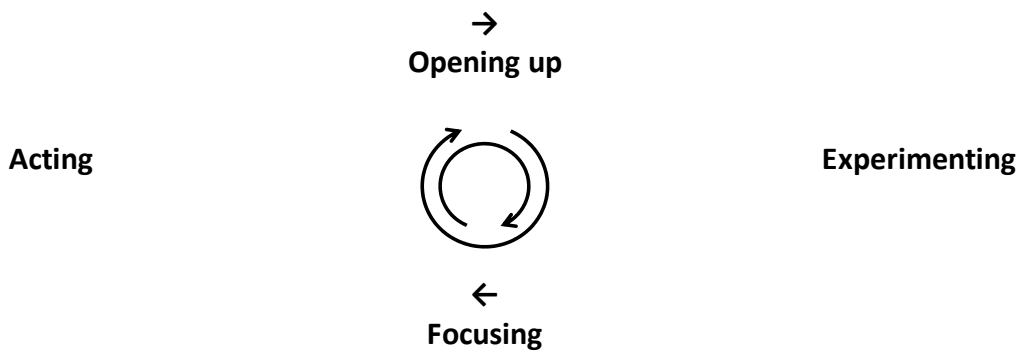

Figure 1. Holmqvist's cyclical model of the dynamics of exploitation and exploration (adapted from Holmqvist 2003, 108).

What is particularly useful for policing is that Holmqvist (2003) writes about bureaucracies and hierarchical power relations (e.g., who has the power to release someone from duty or disregard them). In Holmqvist's (ibid.) study, the question is about intra-organizational learning vs. inter-organizational learning: existing structures within an organization might hinder explorative modes of learning, and thus exploitation prevails. In contrast, between different organizations, in intra-organizational learning, also exploration is possible since cooperation is less formal (as not everyone is within the same hierarchy). Importantly, Holmqvist (2003) claims that in situations with more institutionalized power relations, opening $u p$ is difficult, and in contrast where power is more absent, focusing becomes the problem. In this article, we depict policing as a multi-actor complex, that has traits from intra- and interorganizational learning, but we can understand the police as an organization that has structures that are historically and traditionally bureaucratic and hierarchical (Huotari 2021). 
Hence, Holmqvist's model might help us understand that the step of opening up might be particularly difficult in the police. The risk would be that exploration would be exploration only on the surface (cf. the new artefact as a hammer to hit nails with).

While the ambidextrous organization in the public sector has become an emerging research stream (see Gieske et al. 2019; Cannaerts et al. 2016; Smith \& Umans2015), toour understanding this theoretical lens has not been fully utilised to support the public sector and specifically policing in using AI. In the next section, we will advance this work, as we elaborate on the role of AI within the existing structures of policing (i.e., the use of AI is task-dependent, in Leese 2021). We claim that a focus on exploration inside the task-dependent environment of today might become counterproductive if it does not allow rethinking of problems in current structures. Although this claim is compatible with recent studies on AI in policing (Berk 2021; Egbert \& Leese 2021; Hälterlein 2021; Leese 2021), we propose that Holmqvist's model helps develop a nuanced approach to policing that could open itself up to exploration. Next, we will elaborate on this thought by examining the opportunities and challenges related to exploration with AI inside and outside today's task-dependent environment, before proposing a framework for ambidextrous use of $\mathrm{AI}$ in policing in our conclusions.

\section{AMBIDEXTROUS UTILISATION OF ARTIFICIAL INTELLIGENCE IN POLICING}

In general, when police add AI and algorithms into their toolbox, perhaps the essential question does not lie in what is possible, but what is advisable. However, in terms of ambidexterity, both questions would be necessary. To become ambidextrous, an organization requires exploitation as well. Here, Holmqvist's (2003) work becomes particularly important, as it offers a way to look at exploitation and exploration as a continuing cycle with dynamics: as much of the pioneering AI work within policing is still by definition exploration (cf. March 1991), at some point exploitation follows (Holmqvist 2003), and it might not be far. A simple AI solution based on algorithms and data can, for instance, go through documents much more efficiently than a human police officer. After a while, even a more explorational AI application could become business as usual and activities more exploitational through acting (Holmqvist, 2003).

However, much of the work still highlights the technological capabilities of AI to solve problems already known - it is less debated how police could explore with AI so that it would provide solutions to problems that we do not yet know about (i.e., the unknown unknowns, in McCulloch \& Wilson 2016). Oftentimes, AI in policing merely provides efficiency for solving those issues that are already known. In the following, we label such applications as exploring with AI inside the task-dependent environment of policing. Then, respectively, gaining understanding about new possible causalities and feedback loops within the (in) security environment more openly is labelled as exploring with AI outside the task-dependent environment of policing. We categorise existing AI applications within policing under these labels and address them next.

\section{Opportunities and challenges in exploration with Al inside the task-dependent environment (which is near to exploitation)}

As AI offers technologies to make work more efficient in public administration (Autioniemi 2020; Wirtz et al. 2020; Mehr 2017), numerous types of 'low-hanging fruit' exist in policing as well. What is common across the examined solutions is that many police duties require an immense amount of subjective and intuitive knowledge that is difficult to articulate formally and hence shift to AI (Kaufmann 2019). In this regard, AI has the potential to make existing police duties more efficient, for instance by detecting criminal behaviour, improving reporting of crimes and even anticipating criminal activity (Mehr 2017). Thus, AI allows the police to target its service delivery even before any service orders are assigned to it and then perform reactive responses to service orders more efficiently when needed (CamachoCollados \& Liberatore 2015).

Indeed, through predictive policing, AI could help the police anticipate many kinds 
of crime that it expects to happen in a certain area someday. Predictive policing means cases such as mapping crime hotspots, as well as profiling potential offenders and the most likely victims for given crimes (Kaufmann 2019; Nissan 2017; Tayebi \& Glässer 2016; Lawton 2011). Hot-spot prediction requires data on crime types to map high-risk times and places (Berk 2021; Hardyns \& Rummens 2018), while suspect or victim prediction require data on the characteristics and backgrounds of persons involved in crimes, not data about crimes more generally (Hälterlein 2021). AI can also support the police by predicting the individuals that would most probably associate with some criminal activity under investigation, by going through databases of background information and criminal network intel (Tayebi \& Glässer 2016). Thus, such predictions could make the demanding criminal investigators' work a bit less demanding. In all, AI can complement and replace human work in tasks that are simple or can be simplified, thereby releasing human capacity for more meaningful tasks (Leese 2021) once discretion is used (Kaufmann 2019).

Although predictive policing has been reported to decrease local crime rates (predicting hotspots, in Goldsmith \& Crawford 2014), such cause-and-effect relationship is difficult to prove (Shapiro 2017; Egbert \& Leese 2021). AI can, at worst, exacerbate structural biases (Bacchini \& Lorusso 2019) and feed prevailing preconceptions (Shapiro 2019). Predictive policing has also been criticised for focusing on problems, not on a criminal basis, but on the basis of statistical analysis - raising doubts about discrimination (Leese 2021). A further issue arising from the predictive turn is approaching problems too narrowly and selectively, thereby ignoring certain historical, social, and cultural dimensions (Hälterlein, 2021). Ultimately, there are even the ethical concerns related to precrime punishment of possible future criminal activity (e.g., detainment of an individual already before the crime has been committed, in McCulloch \& Wilson 2016). Indeed, while AI is likely to correct or ignore some biases in human judgment, the benefits do not come without adverse effects (see Degeling \& Berendt 2018).

In all, the 'too narrow', myopic exploration with AI that could improve efficiency might, at the same time, hinder the police from perceiving the in(security) environment and identifying problems in new and richer ways and therefore prevent the enhancement of systemic problemsolving capabilities. To avoid this development, exploration with AI would be needed from outside the task-dependent environment.

\section{Opportunities and challenges in exploration with Al outside the task-dependent environment}

AI operates also within the sphere of unknown problems to support novel problem formulations instead of producing answers to pre-formulated problems (Ziewitz 2016). Thereby, by exploring with AI more openly, the police can reform or reinvent itself by shifting from reactive actions to more proactive ones (Goldsmith \& Crawford 2014; Weisburd \& Majmundar 2018). Predictive policing plays a role here as well, but with a more open-ended agenda for proactive use of AI. This means more future-oriented exploration with possibly unknown end-results.

First, we live in a society that generates data from almost everything we do. Technological devices embedded in urban structures or used by people constantly gather data about people, buildings, vehicles, different forms of consumption, etc. to better serve people's needs and make life more comfortable (Allam \& Dhunny 2019). Smart technology that supports the functioning of contemporary societies and the well-being of their citizens (see e.g., Pelton \& Singh 2019) opens an illustrative prospect for understanding open-ended exploration with AI in policing (Joh 2019). For example, AI could (and can already, though more in a task-oriented way, see Shapiro 2017) augment a patrolling police officer's visibility from their eyesight to the cyberworld, giving them clues whom to focus on and perhaps why; such augmentation would not only be limited to known problems such as identifying license plates, but it could also give the officer more holistic information about what is happening around them (Goldsmith \& Crawford 2014). The same goes with the police as an organization. However, AI requires data that is adequate in quantity and quality which poses limits to such developments (Kaufmann 2019). If actualised, AI could still 
help the police understand and conceptualise (in)security in the smart society and generate new kinds of tasks and performance indicators for policing (Kaufmann 2019). The social media is a showcase of human interaction within the smart society as well. AI could be harnessed not only to fighting but to conceptualising, e.g., extremism in the social media, by making it seek signs of radicalisation from communication streams; AI could then pinpoint individuals behind that communication, and ultimately help the police understand the process of radicalisation better (Fernandez \& Alani 2021). While these opportunities seem promising, using AI along the urban infrastructure would also increase surveillance of the individual, even to Orwellian extents if not used with caution (Chan 2021; Hayward \& Maas 2021; Rowe \& Muir 2021).

Second, some minor policing decisions could be made by AI, even with purposeful end results. Such decisions are, again, easily within the task-environment of today (e.g., automating the process of giving a speeding ticket). However, problems arise when decisionmaking would be done outside today's tasks (Hälterlein 2021; Leese 2021). As it is known, AI cannot contextualise information as humans do (Autioniemi 2020). New technologies, and in particular algorithms that shift decision-making power (or capability) from humans to machines might fail, for reasons of lacking ethicality (Mehr 2017), interpretability (Anastasopoulos \& Whitford 2019), or accountability (Wirtz et al. 2020). Simply put, the responses by AI might later prove wrong and the decision might have to be reversed (Autioniemi 2020). Such reversal could be, e.g., releasing a prisoner that has been judged based on a biased AI algorithm (Wirtz et al. 2020; Brantingham et al. 2018). Sometimes, however, the decision could be irreversible, with damage done already. From the viewpoint of security administration, an example of such situation could be a malfunctioning autonomous system that kills a friendly target that was falsely predicted as being hostile (Wirtz et al. 2020). Moreover, there are challenges related to judgement transparency as it might be difficult (or even impossible) for humans to understand the decision made by AI and the related biases (Kankanhalli et al. 2019).
Third, it is well known that crimes and other events of interest to police are not completely random but follow certain patterns (Felson \& Boba 2010; on crime pattern theory, see e.g., Brantingham \& Brantingham 2011). How well these patterns are understood is still an open question; it could be possible to explore and identify various patterns that might explain different chains of interactions leading to undesirable citizen behaviour. Such pattern recognition would require, on the one hand, the availability of tools that could present the crime pattern data in ways that help the police understand the context of (in)security in novel ways. On the other hand, it would require that the data collected go beyond what is currently known, managed, and made accountable for within the police. These shifts would also change practices about who is allowed to use certain data and for which purposes (cf. Chan \& Moses 2015) - especially, if the purpose is not known beforehand, as with open-ended exploration. If these preconditions are met, AI might help the police identify correlations and causal relations that go beyond the lens of criminal law, thereby identifying problems and interventions that might otherwise go unnoticed, unidentified, under-conceptualised, or ignored. Thus, such more open-ended exploration with AI has the potential to illuminate blind spots in policing and understand the (in)security environment by envisioning possible worlds and counterfactual scenarios (see Pearl \& Mackenzie 2018). However, quite understandably, such exploration with AI could very well create unrealistic perceptions of causal relations in the (in)security environment (Berk 2021). Moreover, as such a reconceptualisation would challenge existing structures and practices that are well-established and heavily invested in, implementing AI to serve exploration would be extremely challenging in the wide scale (i.e., changing the focus of exploitation as well, Huotari 2021).

In all, there are opportunities and challenges related to both modes of exploration with AI. Next, we proceed to our conclusions. 


\section{CONCLUSIONS}

As we have presented in this article, policing - even if based on AI - easily functions based on certain logics that stem from existing structures (Shapiro 2021; Kaufmann 2019). We claim that this kind of exploration might be exploration only on the surface. With more open-ended exploration with AI, outside the task-environment of today, the knowledge basis of policing could possibly be revisited. Critically revisiting and challenging the existing structures would then require the dynamics of ambidexterity: opening up to, experimenting with, focusing on and acting upon specific AI solutions for policing (cf., Holmqvist 2003). Based on our analysis of AI in policing, we now come back to Holmqvist's (ibid.) work and provide an extended framework that is intended to provide agenda for researchers and practitioners in the area.

As Figure 2 depicts, AI in the context of policing can take numerous different routes. First, the status quo of current acting is questioned by opening up, which enables innovativeness. Then, policing can use AI according to two modes, experimenting either (1) from inside or (2) outside today's task environment, both of which have their opportunities and challenges. We propose that the two modes can be used exclusively, in tandem or sequentially. Then, focusing on certain selected solutions would follow, requiring processes to implement the newly invented working practices. Finally, the new working solutions can become used by the police in their daily work, and thus AI is exploited by acting. Figure 2 also conveys the message that an innovative work mode (exploration) might coexist with a mode that tries to achieve the traditional goals (exploitation) if this is allowed and resources and legitimacy for both modes are available. This way ambidexterity becomes not only a grandiose goal but organizational practice in policing.

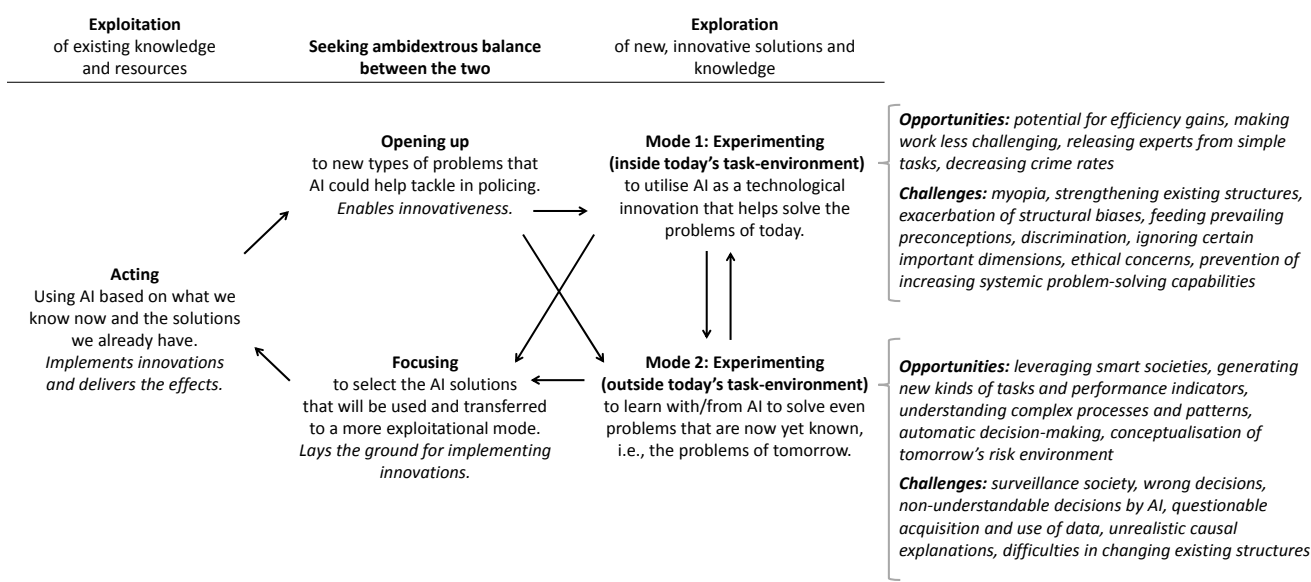

Figure 2. Our proposed framework for Al in the context of policing extends Holmqvist's (2003) work.

As Figure 2 illustrates, while technology has changed and will change the police's capacity in desired areas, it is also likely to bring ineffective, inappropriate, and frustrating consequences as well. Considering the rapid change and complexity in the (in)security environment, it would be necessary but insufficient for the police to become more developed and sophisticated in solving sectored problem formulations. Thus, it would be important to perceive more broadly the processes of crime and other unwanted behaviour as well as the role of the police itself in these processes. This requires exploration in mode 2, outside today's task environment.

The key contribution of this paper to literature is showing the need to understand $\mathrm{AI}$ in policing outside the task-dependent environment of today. Without using exploration in mode 2 , 
AI has the potential to strengthen the existing structures and work even counterproductively. Therefore, to respond to yet unknown problems, exploration needs to take forms beyond seeking efficiency and prediction in questions that we already know, since new types of questions might have to be raised. This contribution has significance for both researchers and administrative practitioners.

We suggest that researchers of AI in policing take on our mode- 2 exploration with AI. An important future research avenue lies in the fact that the operational environment is increasingly complex but policing and police work are structured, and technologies might offer either a solution or a turn for worse (Berk 2021; Skogan 2006). Administrative and general management research is hence needed to understand how AI produces new types of policing without reproducing the rigid structures and even increasing their rigidness. At the same time, it would be necessary for researchers to examine how AI could help administrators become more accountable for issues than before, and not make people avoid responsibility or shift it to AI.

We have also sought to create some inspiring thoughts for administrative practitioners. We understand that typically administrative practice entails only minor chances to work outside predetermined problems and solve unknown issues. However, we claim that the issues that lie beyond today's task-dependent environment might not always be something mysterious or concern wide security threats. Instead, the 'open-ended exploration type of thinking' might reveal something fundamental yet interesting about quite mundane working practices that we everyday face, or about problems that we do not know of yet - even if we probably should. For example, more open-ended exploration with AI could help discover systematic racism in policing, or remove systematic biases in searching, arresting, charging or conviction of ethnicities, age groups or geographical groups.

Finally, by learning from policing, we claim that our findings could be useful for other branches of public administration as well. Thus, further studies are encouraged to examine (a) the counterproductive aspects of utilising AI too narrowly, with focus on the task-dependent environment of today, and (b) the possibilities for exploring with $\mathrm{AI}$ in different contexts, with a more open-ended agenda. As our study only scratches the surface on these topics and raises the need to further study the more open-ended exploratory aspects of AI too, there is much room to advance the area.

\section{ACKNOWLEDGEMENTS}

Tuomas Korhonen and Teemu Laine wish to express their appreciation to Business Finland (the Finnish government organization for innovation funding and trade, travel and investment promotion) for funding this work, especially the project 'NewBI5 - New competitiveness and Business Impact from Intelligence, Intuition, Integration and Interaction'. Ossi Heino, who is currently working at Tampere University, wishes to express his gratitude to the Academy of Finland [decision no. 315074] for its financial support.

\section{REFERENCES}

Allam, Zaheer \& Dhunny, Zaynah (2019). On big data, artificial intelligence and smart cities. Cities, 89, 80-91. https://doi.org/10.1016/j.cities.2019.01.032

Anastasopoulos, Jason \& Whitford, Andrew (2019). Machine learning for public administration research, with application to organizational reputation. Journal of Public Administration Research and Theory, 29(3), 491-510. https://doi.org/10.1093/jopart/muy060

Autioniemi, Jari (2020). Tekoälyn yhteiskehittäminen julkisella sektorilla. Hallinnon Tutkimus, 39(1), 5-20. https://doi.org/10.37450/ht.98075

Bacchini, Fabio \& Lorusso, Ludovica (2019). Race, again: how face recognition technology reinforces racial discrimination. Journal of Information, Communication and Ethics in Society, 17(3), pp. 321-335. https://doi.org/10.1108/JICES-05-2018-0050

Bain, Andy (2016). Horses and Horsepower, Fingerprints and Forensics: The Development of Technology and Law Enforcement. In Bain, Andy (Ed.) Law Enforcement and Technology: Understanding the Use of Technology for Policing (pp. 9-25). London: Palgrave Macmillan. https://doi.org/10.1057/978-1-137-57915-7_2 
Berk, Richard (2021). Artificial Intelligence, Predictive Policing, and Risk Assessment for Law Enforcement. Annual Review of Criminology, 4(1), 209-237.

https://doi.org/10.1146/annurev-criminol-051520-012342

Bland, Matthew (2020). Algorithms Can Predict Domestic Abuse, But Should We Let Them?. In Jahankhani, Hamid, Akhgar, Babak, Dastbaz, Mohammad \& Cochrane, Peter (Eds.) Policing in the Era of AI and Smart Societies (pp. 139-155). Springer, Cham. https:/doi.org/10.1007/978-3-030-50613-1_6

Braga, Anthony \& Weisburd, David (2006). Conclusion: Police innovation and the future of policing. In Weisburd, David \& Braga, Anthony (Eds.) Police Innovation: Contrasting Perspectives (pp. 339-352). Cambridge: Cambridge University Press.

https://doi.org/10.1017/

CBO9780511489334.018

Brantingham, Jeffrey, Valasik, Matthew \& Mohler, George (2018). Does predictive policing lead to biased arrests? Results from a randomized controlled trial. Statistics and public policy, 5(1), $1-6$.

https://doi.org/10.1080/233044

3X.2018.1438940

Brantingham, Paul \& Brantingham, Patricia (2011). Crime pattern theory. In Wortley, Richard \& Mazerolle, Lorraine (Eds.) Environmental Criminology and Crime Analysis (pp. 78-93). London: Routledge.

Brewster, Ben, Kemp, Benn, Galehbakhtiari, Sara \& Akhgar, Babak (2015). Cybercrime: Attack Motivations and Implications for Big Data and National Security. In Akhgar, Babak, Saathoff, Gregory, Arabnia, Hamid, Hill, Richard, Staniforth, Andrew \& Bayerl, Petra Saskia (Eds.) Application of Big Data for National Security: A Practitioner's Guide to Emerging Technologies (pp. 108-127). Oxford: Butterworth-Heinemann. https://doi.org/10.1016/B978-0-12-8019672.00008-2

Camacho-Collados, Miguel \& Liberatore, Federico (2015). A Decision Support System for predictive police patrolling. Decision Support Systems, 75, 25-37.

https://doi.org/10.1016/j.dss.2015.04.012

Cannaerts, Nele, Segers, Jesse \& Henderickx, Erik (2016). Ambidextrous design and public organizations: a comparative case study. International Journal of Public Sector Management, 29(7), 708-724.

https://doi.org/10.1108/IJPSM-12-2015-0210
Chan, Janet. (2021) The future of AI in policing: exploring the sociotechnical imaginaries. In McDaniel, John L.M., Pease, Ken G. (Eds.) Predictive Policing and Artificial Intelligence. London: Routledge, pp. 41-57. https://doi.org/10.4324/9780429265365-3

Chan, Janet \& Moses, Lyria Bennett (2015). Is Big Data challenging criminology? Theoretical Criminology, 20(1), 21-39. https://doi.org/10.1177/1362480615586614

Degeling, Martin \& Berendt, Bettina (2018). What is wrong about Robocops as consultants? A technology-centric critique of predictive policing. AI \& Society, 33(3), 47-356.

https://doi.org/10.1007/s00146-017-0730-7

Egbert, Simon, \& Leese, Matthias (2021). Criminal Futures: Predictive Policing and Everyday Police Work. Oxon: Routledge. https://doi.org/10.4324/9780429328732

Eloranta, Kari (1986). Tekoälyn älykäs käyttö. Hallinnon Tutkimus, 5(2), 247-274.

Felson, Marcus \& Boba, Rachel (2010). Nine Fallacies About Crime. In Felson, Marcus \& Rachel Boba (Eds.) Crime and Everyday Life (4th edition) (pp. 1-24) London: Sage. https://doi.org/10.4135/9781483349299

Fernandez, Miriam \& Alani, Harith (2021). Artificial intelligence and online extremism: challenges and opportunities. In McDaniel, John L.M., Pease, Ken G. (Eds.) Predictive Policing and Artificial Intelligence. London: Routledge, pp. 132-162. https://doi.org/10.4324/9780429265365-7

Gieske, Hanneke, van Meerkerk, Ingmar, \& van Buuren, Arwin (2019). The impact of innovation and optimization on public sector performance: testing the contribution of connective, ambidextrous, and learning capabilities. Public Performance \& Management Review, 42(2), 432-460.

https://doi.org/10.1080/15309576.2018.1470014

Girasa, Rosario (2020). Artificial Intelligence as a Disruptive Technology: Economic Transformation and Government Regulation. Cham: Palgrave Macmillan. https://doi.org/10.1007/978-3-030-35975-1

Goldsmith, Stephen, \& Crawford, Susan (2014). The responsive city: Engaging communities through data-smart governance. John Wiley \& Sons.

Hardyns, Wim \& Rummens, Anneleen (2018). Predictive Policing as a New Tool for Law Enforcement? Recent Developments and Challenges. European Journal on Criminal Policy and Research, 24(3), 201-218. https://doi.org/10.1007/s10610-017-9361-2 
Hayward, Keith J., \& Maas, Matthijs. M. (2021). Artificial intelligence and crime: A primer for criminologists. Crime, Media, Culture: An International Journal, 17(2), 209-233. https://doi.org/10.1177/1741659020917434

Holmqvist, Mikael (2003). A dynamic model of intra-and interorganizational learning. Organization Studies, 24(1), 95-123. https://doi.org/10.1177/0170840603024001684

Huotari, Vesa (Ed.) (2021). Innovations and Innovativeness in the Police \& Policing: Essays on History, Theory and Philosophy. Police University College Research Reports, 46. https://urn.fi/URN:NBN:fi-fe2021060834969

Hälterlein, Jens (2021). Epistemologies of predictive policing: Mathematical social science, social physics and machine learning. Big Data \& Society, 8(1), https://doi.org/10.1177/20539517211003118

Joh, Elizabeth (2017). Artificial intelligence and policing: First questions. Seattle UL Rev., 41, 1139.

Joh, Elizabeth (2019). Policing the smart city. International Journal of Law in Context, 15(2), 177-182. https://doi.org/10.1017/S1744552319000107

Kankanhalli, Atreyi, Charalabidis, Yannis, \& Mellouli, Sehl (2019). IoT and AI for smart government: A research agenda. Government Information Quarterly, 36(2), 304-309. https://doi.org/10.1016/j.giq.2019.02.003

Kaufmann, Mareile (2019). Who connects the dots?: Agents and agency in predictive policing. In Hoijtink, Marijn \& Leese, Matthias (Eds.) Technology and agency in international relations. London: Routledge. https://doi.org/10.4324/9780429463143-7

Kelleher, John D. (2019). Deep Learning. Cambridge: The MIT Press.

https://doi.org/10.7551/mitpress/11171.001.0001

Lawton, George (2011). Artificial Intelligence Helps Police Serve and Protect. IEEE Intelligent Systems, 26(6), 4-7. https://dx.doi.org/10.1109/MIS.2011.102

Leese, Matthias (2021). Security as Socio-Technical Practice: Predictive Policing and (Non-) Automation. Swiss Political Science Review, 27(1), 150-157. https://doi.org/10.1111/spsr.12432

Lehr, Peter (2019). Counter-Terrorism Technologies: A Critical Assessment. Cham: Springer. https://doi.org/10.1007/978-3-319-90924-0

Macnish, Kevin, Wright, David \& Jiya, Tilimbe (2020). Predictive policing in 2025: A scenario. In Jahankhani, Hamid, Akhgar, Babak, Dastbaz, Mohammad \& Cochrane, Peter (Eds.)
Policing in the Era of AI and Smart Societies (pp. 199-215). Cham: Springer.

https://doi.org/10.1007/978-3-030-50613-1_9

March, James. G. (1991). Exploration and exploitation in organizational learning. Organization Science, 2(1), 71-87.

https://doi.org/10.1287/orsc.2.1.71

McCulloch, Jude \& Wilson, Dean (2016). Precrime: Pre-emption, precaution and the future. Oxon: Routledge. https://doi.org/10.4324/9781315769714

Mehr, Hila (2017). Artificial intelligence for citizen services and government. Harvard Ash Center Technology \& Democracy, no. August, 1-12.

Nissan, Ephraim (2017). Digital technologies and artificial intelligence's present and foreseeable impact on lawyering, judging, policing and law enforcement. AI \& Society, 32(3), 441-464. https://doi.org/10.1007/s00146-015-0596-5

Olsen, Odd Einar, Juhl, Kirsten, Lindoe, Preben H. \& Engen, Ole Andreas (Eds.) (2020). Standardization and Risk Governance: A Multidisciplinary Approach. Taylor \& Francis. https://doi.org/10.4324/9780429290817

Pearl, Judea \& Mackenzie, Dana (2018). The Book of Why: The New Science of Cause and Effect. New York: Basic Books.

Pelton, Joseph \& Singh, Indu (2019). Smart Cities of Today and Tomorrow: Better Technology, Infrastructure and Security. Cham: Springer. https://doi.org/10.1007/978-3-319-95822-4

Rogers, Colin \& Lewis, Rhobert (2007). Introduction to Police Work. Cullompton: Willan Publishing. dx.doi.org/10.4324/9781843926313

Rowe, Michael (2014). Introduction to Policing (2nd edition). London: Sage.

Rowe, M., Muir, R. (2021) Big data policing: governing the machines? In McDaniel, John L.M., Pease, Ken G. (Eds.) Predictive Policing and Artificial Intelligence. London: Routledge, pp. 254-268.

https://doi.org/10.4324/9780429265365-13

Shapiro, Aaron (2017). Reform predictive policing. Nature, 541(7638), 458-460.

https://doi.org/10.1038/541458a

Shapiro, Aaron (2019). Predictive policing for reform? Indeterminacy and intervention in big data policing. Surveillance \& Society, 17(3/4), 456-472.

https://doi.org/10.24908/ss.v17i3/4.10410

Shapiro, Aaron (2021). Accountability and indeterminacy in predictive policing. In McDaniel, John L.M., Pease, Ken G. (Eds.) Predictive Policing and Artificial Intelligence (pp. 185-213). London: Routledge.

https://doi.org/10.4324/9780429265365-10 
Skogan, Wesley (2006). The promise of community policing. In Weisburd, David \& Anthony Braga (Eds.) Police Innovation: Contrasting Perspectives (pp. 27-43). Cambridge: Cambridge University Press.

https://doi.org/10.1017/ CBO9780511489334.002

Smith, Elin \& Umans, Timurs (2015). Organizational Ambidexterity at the Local Government Level: The effects of managerial focus. Public Management Review, 17(6), $812-833$. https://doi.org/10.1080/14719037.2013.849292

Staniforth, Andrew \& Akhgar, Babak (2015). Harnessing the Power of Big Data to Counter International Terrorism. In Akhgar, Babak, Saathoff, Gregory, Arabnia, Hamid, Hill, Richard, Staniforth, Andrew \& Bayerl, Petra Saskia (Eds.) Application of Big Data for National Security: A Practitioner's Guide to Emerging Technologies (pp. 23-38). Oxford: Butterworth-Heinemann. doi.org/10.1016/B978-0-12-801967-2.00003-3

Sun, Tara Qian, \& Medaglia, Rony (2019). Mapping the challenges of Artificial Intelligence in the public sector: Evidence from public healthcare. Government Information Quarterly, 36(2), 368 -383. https://doi.org/10.1016/j.giq.2018.09.008

Tayebi, Mohammad A, Glässer, Uwe (2016) Social Network Analysis in Predictive Policing: Concepts, Models and Methods. Springer. https://doi.org/10.1007/978-3-319-41492-8
Tushman, Michael L. \& O'Reilly III, Charles A. (1996). Ambidextrous organizations: Managing evolutionary and revolutionary change. California Management Review, 38(4), 8-29. https://doi.org/10.2307/41165852

Weisburd, David \& Majmundar, Malay (Eds.) (2018). Proactive Policing: Effects of Crime and Communities. Washington: The National Academic Press. https://doi.org/10.17226/24928

Weisburd, David \& Braga, Anthony (2006). Introduction: understanding police innovation. In Weisburd, David \& Braga, Anthony (Eds.) Police Innovation: Contrasting Perspectives (pp. 1-23). Cambridge: Cambridge University Press. https://doi.org/10.1017/CBO9780511489334

Whetstone, Thomas, Brodeur, Jean-Paul, Walsh, William Francis, Banton, Michael Parker and Kelling, George L. (2020). "Police”. Encyclopedia Britannica, https://www.britannica.com/topic/ police. Accessed 4.9.2021.

Wirtz, Bernd, Weyerer, Jan \& Sturm, Benjamin (2020). The dark sides of artificial intelligence: An integrated AI governance framework for public administration. International Journal of Public Administration, 43(9), 818-829. https://doi.org/10.1080/01900692.2020.1749851 Ziewitz, Malte (2016). Governing Algorithms: Myth, Mess, and Methods. Science, Technology, \& Human Values, 41(1), 3-16. https://doi.org/10.1177/0162243915608948 